(c) The Author(s) 2020. This is an Open Access article, distributed under the terms of the Creative Commons Attribution licence (http:// creativecommons.org/licenses/by/4.0/, which permits unrestricted re-use, distribution, and reproduction in any medium, provided the original work is properly cited. doi:10.1017/S1474746420000202

\title{
Supporting Older Co-Resident Carers of Older People - The Impact of Care Act Implementation in Four Local Authorities in England
}

\section{Gareth O'Rourke*, Liz Lloyd**, Agnes Bezzina***, Ailsa Cameron ${ }^{\dagger}$, Tricia Jessiman ${ }^{\ddagger}$ and Randall Smith ${ }^{\S}$}

*College of Medicine and Health, University of Exeter, UK

E-mail: g.orourke@exeter.ac.uk

**School for Policy Studies, University of Bristol, UK

E-mail: liz.lloyd@bristol.gov.uk

***School for Policy Studies, University of Bristol, UK

E-mail: agnes.bezzina@bristol.ac.uk

${ }^{\dagger}$ School for Policy Studies, University of Bristol, UK

E-mail: A.Cameron@bristol.ac.uk

${ }^{\ddagger}$ Bristol Medical School, University of Bristol, UK

E-mail: Tricia.Jessiman@bristol.ac.uk

${ }^{\S}$ School for Policy Studies, University of Bristol, UK

E-mail: Randall.Smith@bristol.ac.uk

The Care Act 2014 provides for 'parity of esteem' between people with social care needs and carers. This is achieved by extending the principles of prevention and wellbeing to carers; reinforcing carers' right to an assessment; and setting national eligibility criteria for access to carer support services. This article reports on research that examined the impact of these changes on older co-resident carers of older people in four English local authorities. Findings are described in relation to four key themes: organisational arrangements and rationale; the aims of carer support and preventative services; design and delivery of carer assessment; and barriers to assessment and support. The findings of the research suggest that, despite the new statutory requirements, underlying contradictions and tensions in local authorities' relationship with carers, and efforts to support them, remain unresolved.

Keywords: Older carers, Care Act 2014, support.

\section{Introduction}

This article reports on research completed in 2018 on the impact of Care Act implementation on older co-resident carers of older people in four English local authorities. In the English context family members or others who provide physical, practical or emotional support free of charge are defined in law and policy as carers. However, differences exist between carers in terms of the type and level of recognition and support services they receive, and there has been an apparent gap between the stated aims of policies and their impact. The focus of the research, therefore, was on policy implementation; specifically, 
the interpretation of central government policy at local level and translation into service provision. Hence, the legislation and accompanying statutory guidance, and what it requires of local authorities, were leading concerns.

Inevitably, policy interpretation and implementation are influenced by a complex range of interconnected factors within the wider policy process (Hill and Varone, 2017). Here, that includes cultural understandings of caring and perceptions of those who undertake it; the influence of interest groups and individuals; delivery mechanisms, including arrangements between public and voluntary sector organisations (VSOs); and compliance mechanisms, including performance reporting. In addition, the wider socio-economic circumstances in which policy is being implemented are key to outcomes. Continuing austerity at national and local levels; increasing demand for adult social care services; and insufficiency in the social care workforce are all important factors in this instance. All of these factors were shown to have influenced Care Act implementation for carers in the four case study areas to varying extents.

The research findings are discussed through the lens of two particularly pertinent policy perspectives. Caring as a social risk (Morgan, 2018) identifies an inconsistency between the recognition of 'informal' care as a public concern and public provision to protect the wellbeing of carers. Caring as an integrated practice (Tronto, 1993) emerges from the philosophy of care ethics. Caring is regarded as an activity that crosses a perceived moral boundary between public and private domains and calls for appropriate policy responses.

The following brief sections set the scene by describing the Care Act requirements that apply to carers; providing an overview of older carers as a diverse group but with some particular characteristics; and setting out the two policy perspectives mentioned above in a little more detail. This is followed by a description of the research and its findings and then by discussion and conclusions.

\section{Carers and the Care Act 2014}

It is estimated that 8.8 million adults in the UK are carers, providing services to the value of $£ 132$ billion per annum. Each year 2.1 million adults become carers and almost as many see their caring responsibilities come to an end. This 'turnover' means that caring will affect most of the population at some point in their lives (Carers Trust, 2019). The Care Act 2014 builds on earlier legislation (Carers (Recognition and Services) Act 1995; Carers and Disabled Children Act 2000; Carers (Equal Opportunities) Act 2004) with the stated aim of achieving greater recognition and support for carers. These aims are promoted through inter-related provisions in the Act.

The wellbeing principle is extended to carers as well as people with social care needs. This places local authorities under a duty to consider the wellbeing of carers when carrying out statutory care and support functions. The prevention principle is also extended to carers, placing local authorities under a duty to ensure the availability of information and services that prevent, reduce and delay the development of carers' needs.

Local authorities are required to offer carers an assessment that is proportionate to their presenting needs, and provide services to support them where they are found to have eligible needs. In determining a carer's eligibility for services local authorities must 
consider if their caring role is having a significant impact on their wellbeing or their ability to achieve a set of specified outcomes.

\section{Older carers}

There has been a growing interest in older carers as an 'under-reached' group (Yeandle and Wigfield, 2011; see also Age UK, 2010; Carers UK, 2015; Carers Trust, 2019). This is unsurprising given the relief they provide to the health and social care system. More than one million carers in the UK are aged sixty-five or over. Almost one in ten people aged eighty-five or over provide some unpaid care. Most carers aged seventy or over provide more than sixty hours of care per week (Carers Trust, 2019).

Key considerations for policy and practice include the health and care profile of older carers, with many being both provider and recipient of care (Carers UK, 2016; Carers Trust, 2019); the 'reversed' gender profile of carers aged eighty-five or over, with three out of five being male; and the increasing number of older carers from black, Asian and minority ethnic (BAME) communities (Carers UK, 2016; see also Dahlberg et al., 2007; Pound and Greenwood, 2016).

There is a significant body of international literature providing insights into the circumstances and experience of older carers, including a systematic review of eighteen studies (Greenwood and Smith, 2016). It is noteworthy that whilst the quantitative studies reviewed usually confirmed negative effects of caring, qualitative studies often revealed compensations and benefits within the subjective experience of older carers:

It should not be assumed that caring always has a negative effect on older carers or that they always want or need support. Caring can be mutual and satisfying and support provided should be focussed on what these older carers and those they care for want (Greenwood and Smith, 2016: 171).

Caring as a positive and rewarding aspect of later life is a finding of many other studies. Older carers' role satisfaction has been linked to maintaining continuity with earlier life, feeling wanted and purposeful in old age, and adopting roles previously occupied by the cared for spouse (Pollitt et al., 1991); a sense of job satisfaction, continuing reciprocity, mutual affection and companionship, and fulfilment of a sense of duty (Murray et al., 1999); nurturing, and feelings of commitment, responsibility and devotion (Russell, 2001); social honour and pride in new competencies (Ribeiro and Paul, 2008).

However, such compensations and benefits may be absent, reversed or outweighed. Many older carers experience a sense of invisibility, loss, frustration, social isolation and subordination of their own needs. The latter being exacerbated by the tendency of professionals to focus on the cared for person (Pollitt et al., 1991; Murray et al., 1999; Russell, 2001; Ribeiro and Paul, 2008). Glendinning et al. (2015) demonstrate how carers are frequently regarded as both 'resource' in helping the cared for person articulate needs and preferences; and 'co-worker' through expectations of their willingness and ability to provide personalised care (see also Twigg, 1989).

Positive and negative experiences of older co-resident carers are mediated by the socio-economic contexts in which caring takes place; the health status (physical and mental) of carers and cared for; the nature and level of support provided by family, 
community and the state; and gendered constructions of caring (Greenwood and Smith, 2016). These external factors interact with dynamics within each caring dyad to accommodate caring within an 'extraordinary normalcy' of everyday life (Guest and Corrigan, 2008); and to resist 'custodial caring' - by preserving some semblance of former identities, intimate relationships and home life (Askham et al., 2006; see also Harris et al., 2011; Anderson and Keating, 2018).

\section{Policy perspectives on caring}

\section{Caring as a social risk}

Morgan (2018) draws on the social risk literature to frame policy research into 'informal' care as a contingency in the English welfare system. Caring might be regarded as a contingency in a social policy context in that it can be predicted at population but not individual level, (although specific characteristics e.g. age and gender render some more vulnerable to becoming carers); and it is a provision upon which the health and social care system depends heavily, with potential for significant damage to wider socio-economic interests in the event of institutional failure.

Social risks threaten the wellbeing of the risk bearers, in this case both carers and cared for, in some significant way. Policy makers may respond by leaving the risks privatised to the risk bearers or by enacting policy that provides them with social protection. Morgan's research was not restricted to older carers or a specific focus on health and social care. Nevertheless, the important and highly relevant conclusion reached was that whilst caring is recognised as a social risk in the English welfare system it is not consistently treated as one in policy and in practice. As a result, many aspects of risk remain privatised; different groups of carers receive different levels of protection; and a number of 'secondary' risks have been created, e.g. through unresolved conflict of interests between carers and cared for.

\section{Caring as an integrated practice (care ethics)}

Tronto (1993: 105-08; 127-37) offers an 'ideal type' of care as an integrated practice comprised of four phases, each underpinned by a governing principle. Caring about involves the recognition that a need exists, and that care is necessary. It is underpinned by the principle of attentiveness. Taking care of involves determining what action to take in order to respond to a need and is underpinned by the principle of responsibility. Care giving involves the direct activity of meeting needs by delivering care and is underpinned by the principle of competence. Care receiving involves the care receiver in the process of care through their reaction to it and is under-pinned through the principle of responsiveness.

Tronto's ideal type, developed from the philosophy of care ethics, is highly relevant to policy and practice debates in caring. First, by rejecting a simplistic separation of public and private domains it reveals caring as an activity that extends beyond the caring dyad and articulates a moral claim for the sharing of responsibility through public policy responses. Second, it provides a framework and language through which that shared responsibility might be given practical expression within policies and practices at various levels of society. Third, it locates the cared for person as an active agent in the practice of care, revealing the relational nature of caring through interdependence. 


\section{Support for older carers of older people}

The Support for Older Carers of Older People (SOCOP) study examined the impact of the Care Act 2014 on English local authority provision for older co-resident carers of older people. Specific objectives were:

- To examine Care Act implementation plans of local authorities, paying particular attention to implications for older carers.

- To examine processes of implementation in selected local authorities, as they affect older carers.

- To track the practices of carer assessment in selected local authorities as applied to older carers.

- To identify the strengths, weaknesses and wider implications of these practices.

The first phase of the study involved analysis of the content and usability of local authority websites. This article focusses on the second phase of the study which was undertaken through case studies at four local authority sites in England. The sites were selected because of their differing approaches to Care Act implementation in relation to carers:

- Site 1. Northern city. Responsibility for undertaking carer assessments is contracted out to a VSO. A specialist team operates from the local Carers Centre.

- Site 2. Midland city. Responsibility for undertaking carer assessments is retained within the local authority. A specialist team operates from the Carers Centre located in the city centre library.

- Site 3. Shire county. Responsibility for undertaking carer assessments has been consolidated within a VSO, having previously been shared with the local authority. A specialist team operates from the local Carers Centre.

- Site 4. Coastal town. Responsibility for undertaking most carer assessments is delegated to the multi-disciplinary Enablement Team (not specialist to carers). A separate local authority team provides 'front door' support, information and advice from the local Carers Centre.

\section{Methods}

Case studies were conducted via semi-structured interviews with frontline staff, service managers and commissioners. In addition, three non-participant observations of assessments were undertaken at each site. Table 1 provides the numbers of participants and an outline of the participants' job roles, including whether they worked for the local authority or for a VSO.

Ethical approval was obtained from the Health Research Authority (HRA) Social Care Research Ethics Committee. Participants were provided with information about the study before agreeing to participate and their consent was confirmed immediately prior to interview or observation. Carers were invited to participate by the local authority in the first instance and researchers confirmed that they understood the research and consented to participate immediately before the start of the observed assessment. Where the cared for person was present at the observation, their consent was also confirmed. Interviews were audio recorded and transcribed. Researchers made field notes of observed assessments immediately after each encounter and added further reflections in the post-observation period. Conversations with the assessors, carers and service users were also written up immediately after the assessments. Analysis was undertaken through coding of text data within individual case studies in the first instance. Codes were then compared across case 
Table 1 SOCOP data collection

\begin{tabular}{|c|c|}
\hline Site 1. Northern City. & Site 2. Midlands City. \\
\hline $\begin{array}{l}\text { Interviewees (8): } \\
\text { Local Authority 4: Commissioning Manager; } \\
\text { Commissioning Officer; Project Manager; } \\
\text { Head of Public Engagement. Delivery VSO } \\
\text { 4: Chief Executive / Delivery Lead; Carers } \\
\text { Centre Advisors ( } 3 \text { interviewed together) }\end{array}$ & $\begin{array}{l}\text { Interviewees (5): } \\
\text { Local Authority Carers Team Manager and } \\
\text { Carers Information Officer (interviewed } \\
\text { together); Carer Assessors ( } 3 \text { interviewed } \\
\text { together). }\end{array}$ \\
\hline $\begin{array}{l}\text { Observations (3) } \\
\text { Gender / Age of Carer: F/72 (wife caring for } \\
\text { husband; M/75 (husband caring for wife); } \\
\text { M/70 (son caring for mother). }\end{array}$ & $\begin{array}{l}\text { Observations (3) } \\
\text { Gender / Age of Carer: F/72 (wife caring for } \\
\text { husband); F/72 (wife caring for husband); } \\
\text { M/73 (relationship not specified). }\end{array}$ \\
\hline Site 3. Shire County. & Site 4. Coastal Town. \\
\hline $\begin{array}{l}\text { Interviewees (11): } \\
\text { (Local Authority 2): Carers Project Manager } \\
\text { Local Authority Liaison Officer. (Delivery } \\
\text { VSO 8) Chief Executive; Operations } \\
\text { Manager, Carer Advisors (6). (Older People } \\
\text { VSO 1) Chief Executive. } \\
\text { Observations (3) } \\
\text { Gender / Age of Carer: M/U (husband caring } \\
\text { for wife; F/70 (wife caring for husband); } \\
\text { M/86 and M/50 husband and son caring } \\
\text { for wife / mother). }\end{array}$ & $\begin{array}{l}\text { Interviewees (8): } \\
\text { Local Authority: Commissioning Manager } \\
\text { and Social Work Manager (interviewed } \\
\text { together); Head of Adult Commissioning; } \\
\text { Carers Outreach Worker; Carer Centre } \\
\text { Manager; Carer Assessors (3). } \\
\text { Observations (3) } \\
\text { Gender / Age of Carer: F/66 (wife caring } \\
\text { for husband); F/69 (wife caring for husband); } \\
\text { M/91 (husband caring for wife). }\end{array}$ \\
\hline
\end{tabular}

studies and aggregated into categories. Categories were then further refined into themes. Data displays were constructed to arrange data across case study sites according to emerging categories and themes. Similar procedures and analytical techniques are described by Miles and Huberman, 1994; Strauss and Corbin, 2008; and Flick, 2009.

\section{Limitations}

The method did not include interviews with carers. Instead, direct insights were gained during observations of practice. This was because the primary focus was on policy and practice in accordance with the aims of the study. In some instances, carers were telephoned by the researcher following the observation of their assessment, but these contacts did not yield any further major insights. This is acknowledged as a limitation and an objective for future research might be to explore older carers' subjective experience in more depth.

\section{Findings}

\section{Organisational arrangements and rationale}

In two sites VSOs had been commissioned to undertake carer assessments via a competitive tender exercise. In both cases a local, carer specific, VSO had won the 
contract. Performance improvement was the key rationale for out-sourcing in both sites. In Site 1 (Northern city) this was linked to the local authority's own poor track record in undertaking carer assessments, combined with a perception that carers were less of a focus for the local authority than users of social care:

So actually, that was the decision that was made in [...]. It's a very clear intention that said, 'We're not very good at talking to carers or knowing what carers want, and actually our vast majority of our time is on the service user'. So let's give that whole view around carers too, to an organisation that's much more tuned in to carers. (Commissioning Manager Site 1)

Demanding targets for the number of assessments had been set, and there was a clear expectation of delivery within the fixed budget of the contract. The VSO Chief Executive expected to achieve this by being 'more efficient and less bureaucratic'.

In Site 3 (Shire county), previous partnership arrangements had led to lack of clarity about which organisations should undertake carer assessments. Outsourcing was intended to consolidate responsibility within the contracted VSO. Targets for the number of carer assessments were being negotiated. It was accepted that the target would significantly exceed the total activity in the previous (pre-contract) year.

In the remaining two sites the local authority had retained responsibility for undertaking carer assessments 'in-house'. In Site 2 (Midlands city) a specialist team operated from a base within the city centre library. The decision to retain the service in-house was linked to its strategic importance and confirmation of high quality and performance following evaluation by external consultants. Interviewees reported that the service was widely regarded as being separate from the local authority. This, they asserted, was important, as it made it more acceptable for carers to use, not being subject to negative perceptions of other local authority services. The possibility of close working with the wider adult social care service was cited as an advantage of the service being retained inhouse but contradicted somewhat by the small number and poor quality of referrals made by social workers.

In Site 4 (Coastal town) staff in the multi-disciplinary Enablement Team responded to most new referrals, including requests for carer assessments. Carer assessments could also be carried out by locality or specialist teams if the cared for person was known to them. A separate local authority team acted as 'front door' for carers, providing initial support, advice and information, and referring them to the Enablement Team (or others) for assessment.

The rationale for the operating model adopted in Site 4 was less clear than in other sites. Carer assessment was more incorporated into the mainstream of adult social care services, but there was a strong element of semi-detachment by popular design in the way that the Carers Centre provided a separate front door:

A lot of our carers don't want to necessarily deal with social services. They see us set aside. So, they'll come and talk through to us. (Carers Centre Coordinator Site 4)

\section{The aims of carer support and preventative services}

The Care Act provides for two separate but related aims of carer support: help to continue caring; and help to have a life outside of caring. In all four sites, the much stronger emphasis was on the former. This was most clearly articulated in Site 1: 
For me the huge priority is making carers more - I mean, they're phenomenally resilient. They're probably the most resilient group of people that we have in the city, but actually we need them to be more resilient or to recognise things to do, coping mechanisms, earlier, to look at maybe wider family support etc. (Commissioning Manager Site 1)

Similar views were expressed in all of the other sites. The limited references to supporting carers to have a life outside of caring were frequently linked to 'self-help' and/or 'signposting' to universal (voluntary and community) services that could be accessed at no cost to the local authority. Several interviewees identified difficulties with this approach: notably, the reduced and still shrinking stock of such services after public sector disinvestment linked to austerity.

The budget for the carer assessment service in Site 3 had been assembled by discontinuing grants previously awarded to smaller VSOs for carer related support. The VSO Chief Executive acknowledged the negative impact on other VSOs, some of which had introduced charges for services that were previously free to use. Others pointed out the difficulties for carers of being able to recognise a life outside of caring as a need let alone seeking ways of meeting it, without active support to do so.

Beneath the emphasis on reaching more carers, there was an equally strong emphasis on targeting those in greatest need:

[We] want to have as many carers being triaged so we can identify those most at need, because if we can target people on the cusp of carer collapse, we can help the whole system. (Chief Executive, Delivery VSO, Site 3)

This linked to the application of eligibility criteria that restricted access to services, particularly those that might facilitate a life outside of caring. In Sites 2 and 3 the Care Act national eligibility criteria were being applied to carers in receipt of annual grants previously provided with little or no restrictions as to use. Some were deemed ineligible for new style personal budgets that could only be used for specified services in direct support of their caring role. Similar scrutiny and restrictions were being applied to carers' personal budgets in the other two sites.

This instrumental approach was borne out in the observations of carer assessments. Whilst assessors were generally very sensitive to carers' personal situations, support planning was focussed on how tasks of caring could be supported. This was the case even when the social and emotional consequences of caring were identified as needs.

\section{Design and delivery of carer assessment}

The Care Act requires that carers are offered a proportionate assessment of their own needs. This must be separate from any needs assessment of the person they care for, unless both carer and cared person give informed consent for a joint assessment.

Different approaches had been adopted in the four sites. All undertook some form of screening prior to full assessment; two sites operated tiered systems of assessment. In Site 1, a continuum of three tiers of assessment was linked to service response. Triage accessed emotional first aid, information and registration as a carer; Tier 1 assessment accessed signposting to universal services; Tier 2 assessment accessed funded support. Carers 
moved through the continuum when the service response in the previous tier was thought (or had proven) to be inadequate.

In Site 3 a pathway of two hours assessment followed by eight hours of intervention work had been developed. Full implementation of the pathway had not been possible due to resource constraints. Carers with 'lower level' needs were being signposted following triage, and the pathway was being compressed into shorter periods for others.

In Site 2 initial screening was undertaken by the specialist carers team who went on to undertake an assessment if the level of need called for one. Similarly, in Site 4 requests for carer assessments were screened by the specialist front door team before a referral to the Enablement Team if necessary.

Screening, triage and Tier 1 assessment were frequently undertaken by telephone. In Site 1, the contract was only viable for the VSO on the basis of approximately 50 per cent of assessments being conducted via telephone. Front line workers had voiced concern about the heavy reliance on telephone assessments. They considered them to be less than ideal because of the absence of visual prompts and clues about needs, and less certainty about the subject's understanding of the process.

In the two VSO delivery sites, and in Site 2, assessors were not registered professionals. In all three of these sites a core group of staff were experienced in working with carers, and there were active training programmes designed to develop staff according to their skills and experience. In Site 3 the local authority had outposted a Liaison Officer to help with quality assurance of assessments and consistent application of eligibility criteria, as well as provide a link into 'mainstream' social care services for the most complex cases. In Site 4 assessors were registered professionals or assistants working under their supervision.

A common theme across all sites was the importance of informality in the conduct of carer assessments. This was considered necessary to put carers at their ease and to guard against giving them the impression it was the quality of their caring that was being assessed. Some interviewees suggested that the concept of assessment might itself be problematic:

... assessment is an unfortunate word. (Carers Team Manager and Information Officer, Site 2).

VSOs embraced the notion of assessment as 'conversation' or 'chat' as in keeping with the values of their sector and preferable to the bureaucracy they associated with local authority practice. However, this did not always translate as intended. The assessment form in Site 3 had recently expanded from one to fourteen pages, and some assessors were observed sticking rigidly to assessment forms, sometimes to the point of insensitivity.

At least two of the carers whose assessments were observed did not understand the purpose of the assessment and were therefore unable to prepare or develop any expectations of it. This was probably true, albeit to a lesser extent, of at least four others. Some assessors failed to give a clear explanation of why the assessment was being carried out and potential outcomes. In most cases carers were not offered a clear account of their rights and which organisation (i.e. the local authority) was responsible for realising them.

Approaches to joint assessments of carer and cared for together were mostly contested. In Site 1, the local authority had declared that no joint assessments would be undertaken. The delivery VSO disagreed with this stance. In Site 2 the adult social care 
service sometimes undertook joint assessments without telling the specialist Carers Team, which had led to some carers 'missing out'. In Site 3 the delivery VSO was unwilling to lead joint assessments but would contribute to them if asked. In Site 4 some joint assessments had been undertaken in the past and there was optimism that more would be undertaken as a result of Care Act implementation.

\section{Barriers to assessment and support for older, co-resident carers}

In Sites 1 and 3 older carers had not been identified as a priority group within the VSO's contracts, unlike others such as young carers, mental health carers and BAME carers. This was linked to older carers' lack of assertiveness as a group:

... the approach that has historically been taken with older people really hasn't changed a great deal, sadly [...] older carers, or carers that are supporting older people are probably going to not get the preferential approach that some other groups do, that are able to exert themselves. (Project Manager, Site 3)

A similar situation existed in Site 2, where carers of working age were identified as an additional priority group. There was concern in Sites 2 and 4 about older male carers being a hard to reach group with unmet needs. This was linked to a wider perception that gendered stereotypes of caring and coping impacted on the willingness of older carers (male and female), to present for assessment and/or accept services. In some cases, grief at 'losing' a partner to dementia was felt to translate into secrecy and shame.

At the same time many older, married carers were said to regard looking after their spouse as a non-negotiable aspect of their marriage 'contract' and an essential aspect of their identity. Mutual exchange of care between spouses was felt to intensify this mindset. Older carers' negative perceptions of 'social services', including fear that the quality of their caring would be questioned was also felt to be a cause of reluctance.

Finally, social and economic circumstances and attitudes played a part in limiting access to services. Social isolation was cited as a problem for older carers in all sites. Many older couples wanted to engage in social activities together without labels of carer / cared for. Limited opportunities to do so were felt to exacerbate social isolation. In addition, older carers seemed less willing to pay for things they regarded as services. Absence of affordable transport also acted to limit access to services.

\section{Discussion}

The findings of the SOCOP research support Morgan's (2018) conclusion that whilst caring is recognised in the English welfare system as a social risk, it is not always treated as one in the translation of policy into practice. This is seen in the way that the aims of carer support were defined and understood at local level, with a primary emphasis on the goal of maintaining carers in their caring role through supporting resilience and promoting self-help.

Although presented in terms of benefits to carers, and without doubting that at least some benefits are realised by at least some carers, there is a bigger picture to consider. Supporting resilience and promoting self-help might also be understood as mechanisms by which the state seeks to ensure that risks remain privatised as much and for as long as 
possible. The relative lack of attention paid to the goal of having a life outside of caring lends itself to similar interpretation. Despite the policy rhetoric, in practice, risk appears to be calculated more in terms of the potential cost of substitute care to local authorities.

This of course is highly influenced by the context of policy implementation. The Care Act has been implemented against a backdrop of unprecedented austerity at national level. Local authority budgets, of which adult social care is usually the largest single component, have been particularly badly affected (Glendinning, 2016). The primary focus on carers in greatest need or at the cusp of breakdown, and the introduction of eligibility criteria for services that were previously more openly accessible, might reasonably be regarded as mechanisms for controlling expenditure, thereby further preventing the socialisation of risk.

In addition, the widespread practice of signposting carers to voluntary and community services, despite significant public sector disinvestment from such services, also increases the likelihood of risks being borne privately e.g. though self-funding or nonprovision. Thus, screening, triage and Tier 1 assessment followed by signposting might be understood as pathways by which more carers are reached but fewer are offered substantive support. Those that do progress to full assessment are increasingly subject to gatekeeping via the application of new eligibility criteria.

Such developments are at odds with the stated aim and intention of extending the Care Act principles of wellbeing and prevention to carers but allow for the appearance of action consistent with them. Whilst primarily serving as means of managing demand through delay, diversion and exclusion (Arksey, 2002), they simultaneously play an important role in concealing the gap between policy and actual practice. Older coresident carers seem to be particularly susceptible to these forms of rationing, especially where they interact with personal perceptions of caring as a duty or labour of love, and with distrust of public services.

It is also important to consider forms of organisational arrangements and their rationale in relation to social risk. Outsourcing (to VSOs) and arm's length services within local authorities reflected a detachment of carer services from the mainstream of adult social care provision. This was often justified by a lack of essential knowledge of carer issues, and of the skills necessary to support carers effectively; and in terms of carers' negative perceptions, which caused them to be less willing to approach their local authority for help.

However, a wider rationale was also apparent. Local authority commissioners sought to secure more for less through competitive tendering processes and contract management; as well as higher numbers of carer assessments to report. In some instances, commissioning strategies flowed from an acknowledgement of past failure towards carers and enabled 'mainstream' adult social care services to create distance from what they considered to be a difficult area of practice. There was a clear disadvantage of this approach i.e. the frequent absence of an holistic view of the needs of carer and cared for, reflected in the failure of any on the sites to establish unproblematic arrangements for joint assessments.

There were also some actual and potential advantages. Firstly, outsourced or armslength services did provide service points that appeared to be more acceptable to carers, particularly older carers seeking emotional support and social contact. User-friendly access points offered a gateway for establishing trusting relationships from which more substantive forms of support could emerge. Secondly, they offered a hub to attract front 
line practitioners and others with a genuine enthusiasm for carer issues; and (potentially) an authoritative platform from which they might develop as policy advocates and exert influence more effectively and more widely. Unfortunately, this potential is likely to be constrained by the lower status of carer support workers, most of whom were not registered professionals, and performance monitoring focussed on quantity of carer assessments over the quality of outcomes achieved through them.

How then do the findings of the SOCOP study match up to Tronto's ideal type of integrated care? Perhaps the first and most significant observation is to note the lack of integration between phases. The attentiveness (caring about) of legislators in extending the Care Act principles of prevention and wellbeing to carers is exercised in isolation from the responsibility (taking care of) placed on local authorities to give it practical expression. Responsibility is then further fragmented between local authorities as commissioners, and VSO's / arm's length services as delivery organisations.

In each case the disconnection is, in large part, attributable to a lack of resources. There does appear to be a recognition that a need exists, in policy rhetoric at least, but the people making that recognition have delegated the task of taking care of it to others. The failure of central government to provide or specify the means by which local government can take responsibility is strongly reflected in the outcomes of the SOCOP study. This includes further dilution of responsibility through local authority commissioning practices, which is often masked by performance reporting focussed on quantity rather than quality.

However, the disconnection between caring about / attentiveness to the needs of carers in policy making and taking care of / responsibility towards them in policy implementation is perhaps only the headline of a more complex story. A further layer of fragmentation is detectable within the SOCOP findings between the phases of care giving and care receiving. Here, the reality of care being produced and consumed simultaneously (Barnes, 2012) is subordinated through the construction of two separate policy subjects - carers and cared for. The interdependence and frequent interchangeability of these two roles, which is a particular feature of co-resident caring amongst older people, goes largely unrecognised.

In many instances this has resulted in something approaching zero sum policy implementation where a new benefit offered to carers is effectively denied or negated through a disbenefit to the person they care for. Older co-resident carers are disproportionately impacted, being regarded as less of a priority than other groups. This is compounded by their tendency to perceive caring as a duty to be borne and their fear of assessment as a process by which the state may call their competence to care into question. For many, that sense of duty and fear, and possibly also of fulfilment gained from caring, compete with the day to day difficulties of caring - in a way that makes it more difficult to express negative impacts on wellbeing that must be demonstrated as eligibility criteria for services.

Older people's reluctance to identify as carers and rejection of 'mainstream' local authority services have influenced the development of different forms of access points and helping relationships. Outsourced and arm's length services offer new spaces that have been shaped by older people in line with what they find comfortable and where they might pursue hopes and expectations as citizens rather than carers. There are some indications that new practices are beginning to emerge from such spaces. This includes informal and conversational styles of assessment, which offer emotional and social support as an entree, and from which more imaginative forms of practical support and 
community inclusion might be negotiated. Such developments contribute to a wider picture of emerging reform in which local authorities are working with individuals, families and communities to find new approaches to deliver on the aims and objectives of the Care Act (see for example Tew et al., 2019).

However, it's important not to overstate this and to match optimism with caution. There is a danger that the person-centred approaches, that many VSOs pride themselves on, will be eroded by bureaucracy 'imported' from the public sector through contract culture; as illustrated by the new fourteen-page assessment form in Site 3. There is also a danger that informality might be used to obscure rights; as illustrated through abbreviated forms of assessment followed by signposting. In each case the danger is amplified by the lesser status of VSOs and those who work in them compared with local authorities populated with registered professionals. Disinvestment from wider social and community infrastructure - including, somewhat perversely, from other carer support services - also inhibits innovative practice and the possibility of new and better policy emerging from it.

\section{Conclusion}

The Care Act 2014 provides renewed acknowledgement of the huge reliance of the UK health and social care system on unpaid carers and seeks to improve the situation of all carers by clarifying and strengthening rights that have developed over the past three decades. Unfortunately, the findings of the SOCOP study suggest that underlying contradictions and tensions in local authorities' relationship with carers and efforts to support them have not been resolved. In some ways Care Act implementation has intensified and legitimised them.

This is particularly so in relation to older carers of older people, for whom giving and receiving care is often an accepted mode of everyday life rather than a particular activity conferring the status of 'carer'. It appears that practice is beginning to emerge in response to this self-perception and hopes for greater social support and inclusion stemming from it. Whilst this is a cause for cautious optimism, the view of carers as peripheral to the mainstream of adult social care and the lasting effects of austerity are barriers to social justice.

\section{References}

Age UK (2010) Invisible but Invaluable: Campaigning for Greater Support for Older Carers. London: Age UK, https://www.ageuk.org.uk/globalassets/age-uk/documents/reports-and-publications/reports-andbriefings/care-support/rb_oct10_invisible_but_invaluable_report.pdf [accessed 05.04.2019].

Anderson, S. and Keating, N. (2018) 'Marriage after the transition to stroke: a systematic review', Ageing and Society, 38, 11, 2241-79.

Arksey, H. (2002) 'Rationed care: assessing the support needs of informal carers in English social services authorities', Journal of Social Policy, 31, 1, 81-101.

Askham, J., Briggs, K., Norman, I. and Redfern, S. (2006) 'Care at home for people with dementia: as in a total institution?', Ageing and Society, 27, 1, 3-24.

Barnes, M. (2012) Care in Everyday Life: An Ethic of Care in Practice, Bristol: The Policy Press.

Care Act 2014, London: HMSO (TSO).

Carers and Disabled Children Act 2000, London: HMSO (TSO).

Carers (Equal Opportunities) Act 2004, London: HMSO (TSO).

Carers (Recognition and Services) Act 1995, London: HMSO. 
Carers Trust (2019) Facts about Carers, https://carers.org/downloads/resources-pdfs/caring-about-oldercarers/caring-about-older-carers.pdf [accessed 05.07.2020].

Carers UK (2015) Caring into Later Life, The Growing Pressure on Older Carers, London: Carers UK.

Carers UK (2016) Evidence for the Carers Strategy: Written Submission from Carers UK, London: Carers UK.

Dahlberg, L., Demack, S. and Bambra, C. (2007) 'Age and gender of informal carers: a population-based study in the UK', Health and Social Care in the Community, 15, 5, 439-45.

Flick, U. (2009) An Introduction to Qualitative Research, $4^{\text {th }}$ edn, London: Sage.

Glendinning, C. (2016) 'Long-term care and austerity in the UK: a growing crisis', in B. Greve (ed.), Long Term Care for the Elderly in Europe: Developments and Prospects, London: Routledge, 107-25.

Glendinning, C., Mitchell, W. and Brooks, J. (2015) 'Ambiguity in practice? Carers' roles in personalised social care in England', Health and Social Care in the Community, 23, 1, 23-32.

Greenwood, N. and Smith, R. (2016) 'The oldest carers: a narrative review and synthesis of the experiences of carers aged over 75 years'. Maturitas, 94, 161-72.

Guest, C. and Corrigan, O. (2008) 'Extraordinary normalcy: home, relationships and identities in narratives of unpaid care', Health and Place, 53, 71-8.

Harris, S., Adams, M., Zubatsky, M. and White, M. (2011) 'A caregiver perspective of how Alzheimer's disease and related disorders affect couple intimacy', Aging and Mental Health, 15, 8, 950-60.

Hill, M. and Varone, F. (2017) The Public Policy Process, $7^{\text {th }}$ edn, London: Routledge.

Miles, M. and Huberman, A. (1994) Qualitative Data Analysis: An Expanded Sourcebook, $2^{\text {nd }}$ edn, London: Sage.

Morgan, F. (2018) 'The treatment of informal care-related risks as social risks: an analysis of the English care policy system', Journal of Social Policy, 47, 1, 179-96.

Murray, J., Schneider, J. and Banerjee, S. (1999) 'EUROCARE: a cross-national study of co-resident spouse carers for people with Alzheimer's disease. II - a qualitative study of the experience of care giving', International Journal of Geriatric Psychiatry, 4, 8, 651-61.

Pollitt, P., Anderson, I. and O'Connor, D. (1991) 'For better or for worse: the experience of caring for an elderly dementing spouse', Ageing and Society, 11, 4, 443-69.

Pound, C. and Greenwood, N. (2016) 'The human dimensions of post-stroke homecare: experiences of older carers from diverse ethnic groups', Disability and Rehabilitation, 38, 20, 1987-99.

Ribeiro, O. and Paul, C. (2008) 'Older male carers and the positive aspects of care', Ageing and Society, 28, $2,165-83$.

Russell, R. (2001) 'In sickness and in health: a qualitative study of elderly men who care for wives with dementia', Journal of Aging Studies, 15, 4, 351-67.

Strauss, A. and Corbin, J. (2008) Basics of Qualitative Research: Techniques and Procedures for Developing Grounded Theory, $3^{\text {rd }}$ edn, London: Sage.

Tew, J., Duggal, S., Carr, S., Ercolani, M., Glasby, J., Kinghorn, P., Miller, R., Newbigging, K., Tanner, D. and Afentou, N. (2019). Implementing the Care Act 2014: Building Social Resources to Prevent, Reduce or Delay Needs for Care and Support in Adult Social Care in England, University of Birmingham, https:// www.birmingham.ac.uk/Documents/college-social-sciences/social-policy/publications/prp-preventionpdf-121219-acc.pdf [accessed 05.04.2019].

Tronto, J. (1993) Moral Boundaries: A Political Argument for an Ethic of Care, London: Routledge.

Twigg, J. (1989) 'Models of carers: how do social care agencies conceptualise their relationship with informal carers?', Journal of Social Policy, 18, 1, 53-66.

Yeandle, S. and Wigfield, A. (2011) New Approaches to Supporting Carers' Health and Well-being: Evidence from the National Carers Strategy Demonstrator Sites Programme. Centre for International Research on Care, Labour and Equalities (CIRCLE), Leeds: University of Leeds. 